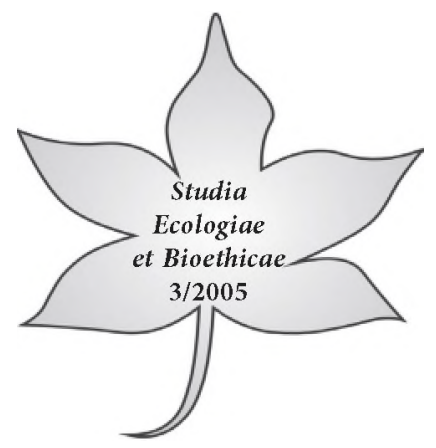

\title{
Wokół Antropologii Środowiskowej - ujęcie zagadnienia przez Patrycję K. Townsend
}

\section{Wstęp}

Antropologia środowiskowa jest terminem dużo szerszym niż sama ekologia, obejmuje bowiem swoim zasięgiem bardzo rozległe i różnorodne zagadnienia. Kwestie środowiskowe znacząco pojawiły się w kręgu zainteresowań antropologii w latach pięćdziesiątych XX w. wraz z ekologią kulturową Juliana Stewarda. Nieco później Andrew Vayda i Roy Rappaport zaproponowali ujęcie określane jako ekologia ekosystemowa. Począwszy od późnych lat siedemdziesiątych bardziej popularna stała się ekologia ewolucyjna. Kolejne podejścia do zagadnień środowiska naturalnego w ramach antropologii to: etnoekologia, ekologia historyczna, ekologia globalna i ekologia krajobrazu. Każde z tych ujęć wniosło coś nowego, akcentując nowe punkty widzenia i dostarczając nowej wiedzy na temat środowiska naturalnego i miejsca oraz roli, jaką pełni w nim człowiek. ${ }^{1}$

\section{Patrycja K. Townsend - przedstawicielka antropologii środowiskowej}

Patrycja K. Townsend w swej książce pt. Environmental Anthropology. From Pigs to Policies przedstawia zasadnicze zagadnienia antropologii środowiskowej. Wydaje się, że samym tytułem wprost nawiązuje do klasycznej już książki z zakresu antropologii kulturowej wydanej w roku 1968 przez Roya A. Rappaporta, zatytułowanej Pigs for the Ancestors. Z drugiej zaś strony sygnalizuje zagadnienia społeczno-polityczne, które są żywo obecne w najnowszych pracach z zakresu antropologii środowiskowej. Nie sposób nie uwzględnić bowiem współczesnych tendencji globalistycznych, handlu międzynarodowego, społecznych ruchów

Por. E. F. Moran, Environmental Anthropology, [w:] D. Levinson (red.), M. Ember (red.), Encyclopedia of Cultural Anthropology, New York: Henry Holt and Company 1996, tom 2, s. 383-387. 
ekologicznych i ich wpływu na decyzje rządów poszczególnych państw i kształtowanie mentalności ich obywateli w sprawach związanych z ochroną środowiska naturalnego. Autorka w sposób jasny i syntetyczny wyraża aktualne tendencje obecne w antropologii środowiskowej. Niebagatelną przyczyną takiego stanu rzeczy są jej naukowe kwalifikacje wzbogacone dużym doświadczeniem w pracach terenowych.

Patrycja K. Townsend jest zatrudniona na stanowisku research associate professor na Wydziale Antropologii Nowojorskiego Uniwersytetu Stanowego w Buffalo. Opublikowała wiele prac, wśród których najbardziej znane to: Medical Anthropology in Ecological Perspective (czwarte wydanie ukazało się nakładem Westview Press w roku 2003) oraz The Peaceful Revolution (drugie wydanie zostało opublikowane w roku 1994 przez Village Housing Trust). Townsend specjalizuje się w badaniu Papui Nowej Gwinei, ze szczególnym uwzględnieniem zagadnień medycznych i kulturowych. W latach 1980-1984 uczestniczyła w projekcie badawczym dotyczącym żyjących tam plemion. Przez wiele lat była czynnym członkiem a później prezesem The Episcopal Christian Caring Fund - organizacji prowadzącej działalność na rzecz uchodźców sudańskich, kurdyjskich i rosyjskich osiedlających się w okolicach Buffalo w stanie Nowy York. W ostatnim czasie zajmuje się badaniem roli organizacji religijnych we wszelkiego rodzaju programach ekologicznych, szczególnie zaś tych promowanych przez rządową Agencję Ochrony Srodowiska USA.

Na szczególną uwagę zasługują prace Patrycji Townsend dotyczące badań z obszaru Papui Nowej Gwinei: Evaluating family health services in Papua New Guinea (1981); Social factors in depo provera use in Papua New Guinea (1981); Evaluating Papua New Guinea's family health programme coverage (1982); Social and economic research concerning nutrition in Papua New Guinea (1982); Mapping maternal and child health coverage in Papua New Guinea (1984); The situation of children in Papua New Guinea (1985) oraz Traditional Birth Attendants in Papua New Guinea: An interim report (1987).

\section{Patrycji K. Townsend ujęcie antropologii środowiskowej}

Patrycja Townsend jest doświadczoną badaczką zagadnień z zakresu antropologii środowiskowej. Swoje podejście do tematu zaprezentowała w ostatniej swojej książce Environmental Anthropology. From Pigs to Policies (Antropologia Srodowiskowa. Od świń do polityki) ${ }^{2}$. Pozycja ta została, przez środowisko naukowe, zgodnie określona, jako przejrzyste i kompetentne wprowadzenie do antropologii środowiskowej. Autorka prezentuje w niej ogólne spojrzenie na tę

2 Książka została wydana w Prospect Heights (USA) w roku 2000 przez Waveland Press. 
gałąź antropologii i przedstawia zasadnicze jej zagadnienia i nurty. Książka składa się z dwunastu chronologicznie uporządkowanych rozdziałów, słownika terminów antropologicznych, spisu uwzględnionej przez Autorkę bibliografii oraz indeksu osobowo-przedmiotowego.

Pomimo braku formalnego podziału książki, można wskazać w niej trzy, wyraźnie zarysowane, części. Rozdziały od pierwszego do szóstego obejmują prezentację historycznych ujęć współczesnej antropologii, natomiast od siódmego do dziesiątego omawiają najbardziej aktualne zagadnienia współczesnej antropologii - wzajemne relacje pomiędzy tym, co lokalne a tym, co globalne. Dwa ostatnie mówią o konieczności zaangażowania się we współczesne problemy ekologiczne i wskazują sposoby ich rozwiązywania. Struktura książki wyznacza zasadnicze zagadnienia, które w opinii Autorki, stanowią podstawę współczesnej antropologii środowiskowej.

We wprowadzeniu Patrycja Townsend opowiada o zetknięciu się z kulturą Papui Nowej Gwinei podczas swych pierwszych prac terenowych. Charakteryzuje też podział antropologii na cztery zasadnicze działy: antropologię biologiczną (fizyczną), archeologię, antropologię kulturową oraz antropologiczną lingwistykę. Do tego tradycyjnego podziału Autorka dołącza coraz częściej wymieniany piąty dział antropologii - antropologię stosowaną (applied anthropology).

Pierwszym ważnym nurtem antropologicznym, który w opinii Townsend, zwrócił uwagę na zagadnienia środowiska naturalnego była ekologia kulturowa zapoczątkowana w USA przez J. H. Stewarda w latach czterdziestych i pięćdziesiątych XX w. Na początku lat sześćdziesiątych etnoekologia i etnobiologia stały się najbardziej popularnymi ujęciami zagadnień środowiskowych. Etnobiologia w istotny sposób wykorzystywała badania lingwistyczne dla zdobycia wiedzy, będącej w posiadaniu kultur tradycyjnych, na temat roślin i zwierząt.

Przedstawiając kolejne ujęcia obecne w antropologii w latach sześćdziesiątych i siedemdziesiątych, Townsend wskazuje, że novum tych ujęć polegało na zaadaptowaniu do antropologii koncepcji i metod spoza tej dyscypliny naukowej. Dotyczyło to głównie zapożyczeń od biologów zainteresowanych ekologią ogólną. Jako przykład takiego podejścia, Autorka przedstawia badania prowadzone w Papui Nowej Gwinei przez Roya A. Rappaporta. Prezentuje także prace kilku antropologów zajmujących się kulturą myśliwską w Amazonii. Są to badania Philippe Descola i Ann-Christine Taylor na temat myśliwskiego plemienia Achuar, żyjącego w tropikalnych lasach Amazonii oraz dorobek Mikea Alvarda, badającego plemię Piro w peruwiańskiej części Amazonii.

Townsend omawia kwestie złożonych społeczności rolniczych porównując je z małymi społecznościami, które nie zajmowały się uprawą roli. Autorka przywołuje pracę Friderika Bartha Ecologic Relationships of Ethnic Groups in Swat, North Pakistan oraz wypracowaną przez niego koncepcję niszy ekologicznej. Townsend prezentuje zmianę w ujęciu antropologii, dzięki zaproponowanej przez Clifforda 
Geertza koncepcji ekosystemu oraz jego propozycję podziału rolniczych ekosystemów Indonezji na swidden i sawah. Prezentuje też wyniki prac, prowadzonych przez Erica Wolfa (Ameryka Łacińska) i Roberta Nettinga (Zachodnia Afryka), z zakresu antropologii ekologicznej oraz badania społeczności ludzkich, prowadzone przez obu tych uczonych, w odizolowanych od zewnętrznego świata wysokogórskich wioskach alpejskich. Wynikiem tych prac było wprowadzenie przez Wolfa terminu political ecology, mającego pomóc w zrozumieniu przystosowania kulturowego poprzez uwzględnienie innych społeczności ludzkich, które podobnie jak warunki biofizyczne, klimat, czy położenie, wpływały na przystosowanie środowiskowe danej społeczności.

Na przykładzie kopalń złota i miedzi, Townsend ukazuje społeczny i środowiskowy wpływ wielkiego przemysłu na społeczności krajów dotychczas nietkniętych piętnem cywilizacji. Autorka przywołuje badania Davida Hyndmana dotyczące kopalni w górach Papui Nowej Gwinei. Przedstawiają one przerażające konsekwencje grabieżczej gospodarki zagranicznych koncernów i lokalnych rządów i ich wpływ na życie plemienia Wopkaimin. Nie jest to jednak problem plemion żyjących tylko na Papui Nowej Gwinei. Podobne zjawiska zauważa się także w innych częściach świata. Stają się one niemal normą wśród wielkich międzynarodowych koncernów i przybierają wymiar globalny.

Townsend omawia także ryzyko związane z nieprzewidywalnymi klęskami żywiołowymi oraz zastosowaniem przez ludzi technologii, aby do minimum zmniejszyć konsekwencje takich sytuacji. Powołuje się na Eliota Fratkina, prowadzącego prace badawcze wśród pasterskiego plemienia Ariaal (północna Kenia), które dywersyfikując swe stada ze względu na odporność zwierząt na brak wody, zabezpiecza się przed wyjątkowo suchymi latami. Autorka przywołuje także prace Rosalind Show, która swoimi badaniami objęła rolników w Bangladeszu, gdzie problemem jest nadmiar wody i częste powodzie. Wskazuje, jak te społeczności radzą sobie z ryzykiem utraty plonów. Townsend przedstawia także eskimoskie plemię Inujjuamuit, żyjące na arktycznych terenach Kanady. Prezentuje sposób, w jaki plemię to radzi sobie z ryzykiem w zdobywaniu pożywienia i przywołuje badania prowadzone w tym względzie przez Ericka A. Smitha. W zależności od sytuacji, Inujjuamit wybierają mniej efektywne, ale pewniejsze sposoby zdobycia jedzenia w okresie niedostatku, ponieważ ryzyko niepowodzenia mogłoby oznaczać śmierć. Natomiast w okresie obfitości Eskimosi mogą pozwolić sobie na próby zdobycia pożywienia, które wymagają mniejszego wkładu energii i rokują znacznie lepsze efekty, ale ich pozytywne rezultaty są mniej prawdopodobne.

Townsend przedstawia także bardzo aktualne zagadnienie demografii człowieka widziane z perspektywy antropologa. Omawia tu badania na temat populacji starożytnych Majów, plemienia!Kung San z Afryki Południowej oraz plemienia Pólnocnych Aché, zamieszkującego na obszarze Paragwaju. Relacjonuje też prace przeprowadzane w indyjskim stanie Kerala, które zaprzeczają powszech- 
nie podzielanemu stereotypowi, że w ubogich społecznościach rolniczych istnieje wysoki odsetek urodzin przy jednoczesnej dużej śmiertelności niemowląt. Populacja plemienia Kerala obejmuje zaledwie 3 procenty ludności Indii, gęstość zaludnienia na zamieszkałym przez nie obszarze jest jednak bardzo wysoka. Według wielu kryteriów, mieszkańcy tej indyjskiej prowincji mieszczą się w standardach państw rozwiniętych. Średnia wieku dla mężczyzn to 69 a dla kobiet 72 lata, podczas gdy w całych Indiach średnia ta osiąga 60 lat. Na tysiąc urodzonych w Kerala niemowląt umiera 11, natomiast średnia dla Indii wynosi 85. Dane te mogłyby wskazywać, że Kerala należą do najzasobniejszych obywateli swojego kraju. Tymczasem jest wprost przeciwnie. Ich średni dochód na osobę jest znacznie niższy od średniego dochodu dla całych Indii. Richard Franke i Barbara Chasin zaznaczają, że przyczyną takiej sytuacji jest ekologia, umiejętność prowadzenia handlu z zagranicą i wypracowane zasady społeczne. Kerala mają długą tradycję organizacji zrzeszającej robotników i drobnych rolników. Organizacje te istotnie wpływają na wprowadzanie programów wspierających biednych w postaci darmowych posiłków w szkołach, rozdawnictwa żywności ubogim, budownictwa komunalnego, dostępu do opieki zdrowotnej i reformy rolnej. Townsend przedstawia także dyskusję na temat korelacji między wielkością populacji i jej wpływem na środowisko naturalne. Przywołuje wnioski Anne i Paula Ehrlichów, zawarte w książce The Population Explosion, w której proponują oni następujący wzór: wpływ na środowisko $=$ populacja $\times$ dobrobyt $\times$ technologia (IPAT: Impact $=$ Population $\times$ Affluence $\times$ Technology). Wydaje się jednak, że jest to znaczne uproszczenie, czego dowodem są badania Williama Durhama i Susan Stonich.

Autorka zwraca także uwage na globalne tendencje zagrażające bioróżnorodności, co w konsekwencji ma ogromny wpływ na ludzkie zdrowie. Powołując się na badania Edwarda Wilsona podaje statystyki mówiące, że 34 tys., tzn. 12,5\% znanych obecnie roślin, jest zagrożonych wyginięciem. Podobne tendencje zauważa się w królestwie zwierząt, a odpowiedzialnym za taki stan rzeczy jest człowiek i jego nieroztropna gospodarka, szczególnie zaś wycinka lasów tropikalnych. Współcześnie proces ginięcia roślin i zwierząt przebiega 10 tys. razy szybciej niż wówczas, gdy na świecie nie było jeszcze człowieka. Antropolodzy przestrzegają, że znikające gatunki flory i fauny są niezbędne dla tworzenia nowych odmian i ras, które są bardziej odporne na warunki atmosferyczne i szkodniki. Wyginięcie ich bezpowrotnie pozbawia nas bogactwa obecnego w przyrodzie. Kolejnym, i to bardziej bezpośrednim, zagrożeniem są ginące gatunki roślin, które tradycyjnie były używane dla leczenia różnych chorób. Znikające lasy tropikalne, będące naturalnym środowiskiem większości tych roślin, przestają już być źródłem ewentualnych lekarstw na pojawiające się wciąż nowe choroby.

Townsend jest świadoma znaczenia rosnących w siłę i znaczenie ruchów ekologicznych dlatego wskazuje na wkład antropologii stosowanej w rozwiązywanie konkretnych problemów ekologicznych. Relacjonuje badania Andrew Vaydy 
na temat pożarów lasów w Indonezji w latach 1997-98. W interesujący sposób przedstawia też relację między prawami zwierząt i prawami człowieka. Ilustruje to sytuacją, jaka miała miejsce w Stanach Zjednoczonych w roku 1999. Indianie Makah zdecydowali się wznowić polowania na wieloryba szarego. Na podstawie porozumienia w Neah Bay z roku 1855 plemię miało zagwarantowane prawo do polowań. Od ponad siedemdziesięciu lat nie korzystało jednak z niego ze względu na zagrożenie tego gatunku. Obecnie populacja wieloryba szarego w pełni się odbudowała i Indianie Makah zdecydowali się wznowić polowania. Ich główną motywacją było odnowienie swojej kultury i tradycji oraz rytuałów z tym związanych. Obrońcy środowiska naturalnego nie sprzeciwiali się decyzji plemienia, ale obrońcy praw zwierząt zaprotestowali w sposób bardzo stanowczy. Patrycja Townsend uważa, że antropologia stosowana może nam pomóc w rozsądnym wyważeniu relacji człowieka względem środowiska naturalnego i rozwiązywaniu sytuacji konfliktowych, jak miało to miejsce w przypadku Indian Makah. Mówi też o indywidualnym stylu życia człowieka i jego wpływie na środowisko naturalne w perspektywie globalnej. Autorka przedstawia badania Rity Erickson przeprowadzone na współczesnych społecznościach konsumpcyjnych. Obserwacjom poddano mieszkańców pewnej małej miejscowości w stanie Minnesota (USA) oraz podobną społeczność mieszkającą w Szwecji. Wyniki badań wskazują, że poza niewielkimi różnicami istniały wielkie podobieństwa w stylu życia obu grup. Pomimo powszechnie wyrażanej pogardy dla materialistycznego i konsumpcyjnego stylu życia, przedstawiciele obu społeczności nieustannie dążyli do powiększenia stanu posiadania, różnili się jedynie preferencjami, co do wyboru pożądanych dóbr. W latach dziewięćdziesiątych obie społeczności zgodnie twierdziły, że dorośli muszą mieć do dyspozycji samochody, podobnie jak dla młodzieży niezbędne jest posiadanie markowych ubrań, a dla dzieci gier video. Różnice wyrażały się tym, że Amerykanie preferowali nowe duże domy, podczas gdy Szwedzi zwracali większą uwagę na efektowne przydomowe ogródki i komfortowe wyposażenie mieszkań. Zarówno w Ameryce, jak i w Szwecji dwie trzecie dochodu gospodarstw domowych brutto było wydawane na dobra konsumpcyjne i usługi. Mentalność konsumenta, który ciągle chce mieć więcej obarcza środowisko naturalne kolejnymi obciążeniami. Podsumowując prezentowane badania Townsend wskazuje, że to właśnie w rękach antropologów znajduje się klucz do zrozumienia sposobu, w jaki człowiek jest w stanie przystosować się do kurczącego się świata.

\section{Zamiast zakończenia}

Niewątpliwą zaletą ujęcia prezentowanych przez Patrycję Townsend tendencji obecnych w antropologii środowiskowej jest bardzo przystępny i zrozumiały styl, którym potrafi prosto przedstawić trudne kwestie i zilustrować je interesu- 
jącymi przykładami. Na uwagę zasługują odwołania do osobistych doświadczeń nabytych przez Autorkę podczas prac terenowych oraz sięganie do tekstów źródłowych. Daje to odbiorcy możliwość osobistej oceny proponowanych rozwiązań i nie zmusza do konieczności zdawania się na opinie innych. Pomimo niewielkich rozmiarów Environmental Anthropology. From Pigs to Policies obejmuje większość zasadniczych zagadnień antropologii środowiskowej i, poza małymi wyjątkami, robi to w sposób rzetelny i syntetyczny.

Zaletą tej prezentacji jest także prowokowanie do stawiania pytań, które mobilizują do pogłębionych poszukiwań. Dotyczy to m.in. pytania o granice wielkości ludzkiej populacji. Czy człowiek jest istotą na tyle pomysłową i przystosowującą się do środowiska, że jest zdolny do przekraczania kolejnych limitów określających, jaka liczba ludzi jest w stanie wyżywić się z dostępnych zasobów? A może właśnie niebezpiecznie zbliżamy się do nieprzekraczalnych granic ekonomicznej wydolności Ziemi? Kolejnym prowokującym pytaniem jest kwestia czynników wpływających na tworzenie się osiadłych i złożonych społeczności. W jakim stopniu i w jakich okolicznościach środowisko naturalne kształtuje i wymusza takie tendencje? Patrycja Townsend skłania nas do stawiania takich i podobnych pytań.

$Z$ całą pewnością pozycja ta nie wyczerpuje rozległej tematyki antropologii ekologicznej, łatwo można wyobrazić sobie gruntowniejsze przedstawienie poszczególnych zagadnień. Autorka zupełnie przemilcza np. kwestie biologiczne i ewolucyjne obecne w ekologii człowieka. Można też zapytać, dlaczego Patrycja Townsend poprzestaje na 119 stronach i nie przedstawia obszerniej dyskusji na poszczególne tematy oraz nie prezentuje szerszego grona przedstawicieli kolejnych ujęć tej dyscypliny naukowej. Skupia się natomiast niemal wyłącznie na ekologii kulturowej i politycznej, traktując marginalnie zagadnienia z pogranicza antropologii i archeologii.

Ilustrując ekologię kulturową Juliana Stewarda, Patrycja Townsend przytacza współczesny przykład nieodpowiedzialnego korzystania z łowisk dorsza na wodach w pobliżu Nowej Funlandii i wskazuje rolę, jaką odegrała w tym zjawisku zmiana technologii połowów. Thomas McGuire - autor artykułu przedstawiającego sytuację nowofunlandzkich łowisk - wyraźnie powołuje się na poglądy Stewarda, choć wymienia także innych uczonych, którzy wpłynęli na sposób, w jaki podszedł on do tego zagadnienia. ${ }^{3}$ Wydaje się, że prezentując badania McGuire'a Patrycja Townsend przeakcentowuje czynnik technologii, jako podstawę ekologii kulturowej. Pomija jednocześnie inne istotne elementy tego stanowiska. Opisując swoją koncepcję Steward wyróżnia trzy procedury leżące

Oprócz koncepcji Juliana Stewarda autor wskazuje także na myśl A. Vaydy oraz M. Schminka i C. Woodsa. Por. T. R. McGuire, The Last Northern Cod, "Journal of Political Ecology", 1997 nr 4, s. 41 . 
u podstaw ekologii kulturowej: (1) analizę relacji pomiędzy systemem zdobywania środków do życia (subsistence system) a środowiskiem; (2) analizę wzorców zachowań połączonych z technologią używaną dla zdobycia środków do życia; (3) ocenę zakresu, w jakim dane wzorce zachowań w konkretnym systemie zdobywania środków do życia wpływają na inne aspekty kultury. ${ }^{4} \mathrm{Z}$ kolei Richard O. Clemmer, analizując koncepcję Stewarda, wyróżnia w niej aż sześć kategorii zmiennych, które wzajemnie na siebie oddziałują: (1) zasoby środowiska naturalnego; (2) technologia używana, aby te zasoby wydobyć, przetworzyć i przechować; (3) społeczna i polityczna organizacja produkcji, ochrony, przeznaczenia i podziału zasobów oraz organizacja ludzkiej pracy dla ich uzyskania; (4) kultura połączona ze wszystkimi powyższymi czynnikami, włączając w to wartości ekonomiczne i wzorce zachowań; (5) biologiczna natura istoty ludzkiej oraz (6) procesy psychiczne i dążenia człowieka. ${ }^{5}$ Wyraźnie więc widać, że technologia potrzebna do zdobycia środków do życia jest tylko jednym z elementów koncepcji określanej jako ekologia kulturowa. Sposób, w jaki Patrycja Townsend przedstawia to zagadnienie wydaje się więc nieco uproszczony i może stwarzać wrażenie jakoby ekologia kulturowa utożsamiała się z analizą technologii używanej dla zdobycia środków niezbędnych do życia. Autorka nie poświęca niemal wcale uwagi pozostałym elementom będącym podstawą ekologii kulturowej, co istotnie deformuje obraz tego stanowiska.

Pewnym brakiem w prezentacji współczesnych tendencji obecnych w antropologii środowiskowej jest pominięcie wpływu na środowisko naturalne wywieranego przez najnowsze technologie. Coraz częściej pojawiają się głosy mówiące o roli, jaką pełnią w tym względzie nano-technologia i inżynierii genetyczna. ${ }^{6}$ Pojawiają się też nowe dyscypliny szczególowe, które istotnie wpisują się we współczesną refleksję nad środowiskiem naturalnym. Chodzi tu o takie dyscypliny, jak eko-ekonomia czy informatyka ekologiczna (computing ecology).?

4 J. H. Steward, Theory of Culture Change. The Methodology of Multilinear Evolution, UrbanaChicago-London: University of Illinois Press 1979, s. 40-42.

5 R. O. Clemmer, Steward's Gap: Why Steward Did Not Use His Theory of Culture Change to Explain Shoshoni Culture Change [w:] R. O. Clemmer (red.), L. D. Meyers (red.), M. E. Rudden (red. ), Julian Steward and the Great Basin. The Making of an Anthropologist, Salt Lake City: The University of Utah Press 1999, s. 153.

6 Por. M. R. Wiesner, V. L. Colvin, Environmental Implications of Emerging Nanotechnologies, [w:] R. Olson (red.), D. Rejeski (red.), Environmentalism \& The Technologies of Tomorrow, Washington-Covelo-London: Island Press 2005, s. 41-52.

7 Por. L. Brown, An Eco-Economy in Harmony with Nature, w: R. Olson (red.), D. Rejeski (red.), Environmentalism os The Technologies of Tomorrow, dz. cyt., s. 20-28; por. takze, F. Zhao, J. S. Brown, Ecological Computing, [w:] R. Olson (red.), D. Rejeski (red.), Environmentalism \& The Technologies of Tomorrow, dz. cyt., s. 53-60. 
Nieco zdawkowa i uproszczona wydaje się też konkluzja książki, że klucz do rozwiązania problemów ekologicznych współczesnego świata leży w rękach antropologów. Ta silna wiara w moc antropologii wydaje się nadmierna. Rozwiązanie globalnych problemów naszej cywilizacji wymaga wszechstronnej współpracy, w którą zaangażują się oprócz antropologów także politycy, autorytety moralne, organizacje pozarządowe oraz specjaliści z innych dyscyplin naukowych. Tylko podjęcie wspólnych działań w celu zdiagnozowania aktualnego stanu środowiska naturalnego i wypracowanie konstruktywnych rozwiązań wydaje się mieć szansę na zahamowanie niebezpiecznych tendencji, grożących środowisku a przez to, pośrednio i bezpośrednio, człowiekowi. Wydaje się, że taka perspektywa rokuje większe szanse sukcesu niż propozycja Patrycji Townsend.

Pomimo wskazanych uproszczeń i pominięć należy uznać propozycję przedstawienia antropologii środowiskowej za bardzo udaną próbę syntezy dotychczasowych osiągnięć z zakresu tej dyscypliny naukowej. Można pogratulować Autorce stylu oraz sposobu, w jaki przedstawia tę, niełatwą przecież, tematykę.

\title{
The issue of the environmental anthropology depicted by Patrycja K. Towsend
}

\begin{abstract}
Environmental anthropology is a much wider term than ecology itself because of its extensive and diverse issues. The environmental questions appeared significantly in athropology in the 1950's with the Julian Steward's cultural ecology. Later Anerw Vayda and Roy Rappaport suggested the term known as ecosystem ecology. From the late 1970's evolutionary ecology has become more popular. The other attempts to the the issues of natural environment within the confines of anthropology are: enthoecology, historic ecology, global ecology and landscape ecology. The article presents environmental anthropology depicted by P.K. Towsed.
\end{abstract}

